\title{
IMPACTO SOCIAL DAS AÇÕES DE UMA ORGANIZAÇÃO SEM FINS LUCRATIVOS
}

\author{
SOCIAL IMPACT OF ACTIONS PROMOTED BY A NON-PROFIT ORGANIZATION
}

\author{
Recebido em 15.01.2018. Aprovado em 18.01.2018 \\ Avaliado pelo sistema double blind review \\ DOI: http://dx.doi.org/10.12712/rpca.v12i1.1193
}

\author{
Vivian Anese \\ Faculdade Meridional (IMED), Passo Fundo/RS, BRASIL \\ anesevivian@gmail.com
}

\section{Carlos Costa}

Faculdade Meridional (IMED), Passo Fundo/RS, BRASIL

carlos.costa1@gmail.com

\section{Elenise Abreu Coelho}

Faculdade Meridional (IMED), Passo Fundo/RS, BRASIL

elenise.ac@gmail.com

\section{Resumo}

O impacto de ações sociais reflete-se na transformação de beneficiários, modificando seu modo de pensar, de viver e de fazer escolhas. Nessa direção, este estudo visou mensurar a percepção de comunidades beneficiárias quanto às ações promovidas por uma organização sem fins lucrativos. A pesquisa, de abordagem quantitativa, descritiva e de cunho transversal, teve a participação de 322 pessoas ligadas à organização nos estados Rio Grande do Sul, Mato Grosso e Rondônia. Assim, como resultados foram avaliados positivamente: a adequação das atividades às demandas locais, o impacto proveniente do trabalho realizado, e, ainda, os benefícios recebidos pelas comunidades atendidas. Do mesmo modo, obteve-se que devem ser melhoradas a divulgação das ações desenvolvidas e as parcerias público-privadas. O estudo mostrou, também, que as ações da organização geram impacto positivo, contribuindo para o desenvolvimento social e a garantia de direitos. Em termos de contribuição, este estudo pretende orientar as organizações sem fins lucrativos na adequação das atividades ofertadas às demandas dos beneficiários.

Palavras-chave: Impacto social. Ações sociais. Organizações sem fins lucrativos.

\begin{abstract}
The social impact of actions is reflected in the transformation of beneficiaries, including changes in their modes of life and decision-making. Benefiting communities' perception of the actions promoted by a nonprofit organization (NPO) were studied using a quantitative, descriptive and transversal approach. A total of 322 individuals interacting with NPOs headquartered in the Brazilian states of Rio Grande do Sul, Mato Grosso and Rondônia were questioned. The suitability of NPO activities in meeting local demands; the benefits accrued and the impact of the work done were positively evaluated. Similarly, the dissemination of the actions and the public-private partnerships developed should be improved. The actions of the NPO generate positive impacts, contributing to social development and the guarantee of rights. This study seeks to provide a guide to NPOs on how to assess the adequacy of the activities offered in response to their beneficiaries' demands.
\end{abstract}

Keywords: Social impact. Social actions. Non-profit organizations. 


\section{Introdução}

O terceiro setor ocupa o espaço existente entre o primeiro setor - composto pela esfera pública - e o segundo setor - constituído pela iniciativa privada (Guimarães, Pinho, \& Leal, 2010). Assim, caracterizase como um conjunto de organizações sem fins lucrativos, estruturadas sob a forma de associações, entidades e instituições, essencialmente designadas a atender os interesses sociais (Fernandes, 1994; Tavares Neto \& Fernandes, 2010). Desse modo, as ações de tais organizações oferecem assistência às populações sendo uma alternativa na promoção do desenvolvimento social (Costa, 2017; Maciel \& Castilhos, 2012; Mañas \& Medeiros, 2012).

Segundo dados do Mapa das Organizações da Sociedade Civil (OSC/2016), essas organizações, no Brasil, chegam a 323 mil, das quais 44\% localizamse na região sudeste, $22 \%$ na região nordeste, $6 \%$ na região centro oeste, $6 \%$ na região norte e $22 \%$ na região sul. Tais organizações são constituídas e dirigidas por membros da sociedade, engajados em causas voltadas para o bem comum, especialmente para a melhora da qualidade de vida das populações em situação de vulnerabilidade social (Marinho, Bezerra, Oliveira, Lima, \& Santos, 2011).

Embora existam há bastante tempo no Brasil, foi no século XX que se verificou significativo crescimento das organizações do terceiro setor. Isso, em razão de que o cenário de crise política e econômica intensificou problemas sociais, como pobreza e fome, e ampliou a precariedade na oferta de serviços públicos, como educação e saúde (Machado \& Bulgacov, 2010; Marinho et al., 2011).

Nesse contexto, com o intuito de promover maior participação social nas questões políticas e garantir acesso aos serviços básicos, emergiu o trabalho do terceiro setor, para preencher a lacuna entre setor público e iniciativa privada (Guimarães et al., 2010). Sob esse aspecto, o terceiro setor é um espaço de participação e mobilização social importante para o desenvolvimento da democracia e para o enfrentamento dos problemas sociais, que contribui enormemente para o bem-estar das partes interessadas (Maguirre, Ruelas, \& Torre, 2016).

Contudo, em suas raízes históricas, as ações das organizações sem fins lucrativos foram, de modo geral, pautadas pela lógica assistencialista, na qual prevalecem a caridade e o paternalismo, que proporcionam ajuda às pessoas, mas não oferecem condições para que se desenvolvam como cidadãos de direitos (Alayon, 1995). No Brasil, somente após a reforma que instituiu a assistência social como política, regulamentada pela Lei Orgânica da Assistência Social (LOAS) (Lei no 8.742, 1993), houve novo direcionamento das ações das organizações do terceiro setor pautadas pela política de assistência social.

Conforme Muraro e Lima (2003) e Tavares Neto e Fernandes (2010), o terceiro setor pode ser dividido em categorias de acordo com as especificidades e os objetivos do serviço oferecido. Assim, as associações têm seu foco no interesse dos participantes que se unem em prol de um objetivo; as organizações não governamentais (ONGs) engajam-se na luta pela garantia de direitos e igualdade social, não visando apenas a atos de caridade; as fundações privadas, por meio de parcerias com o segundo setor, realizam ações de promoção de saúde, educação, dentre outros serviços; as instituições filantrópicas, por sua vez, conformadas pelo caráter assistencialista e pautadas especialmente pela solidariedade e pelo serviço à comunidade (dentre essas creches, abrigos, orfanatos) realizam atividades beneficentes às populações de baixa renda.

Não desconsiderando nenhuma dessas categorias de organizações sem fins lucrativos, mas aproximandose do objetivo deste estudo, particulariza-se a atuação das ONGs, que de caráter essencialmente assistencial, trabalham em prol da capacitação das pessoas por meio da geração de emprego e renda, proporcionando atividades nas quais possam exercitar suas aptidões e potencialidades, com o objetivo de despertar seu protagonismo (Custódio, Jacques, \& Quintana, 2013; Mañas \& Medeiros, 2012). Tal qual o primeiro e segundo setores, elas contribuem ativamente para a movimentação da economia (Costa, 2017; Guimarães, Pinho \& Leal, 2010). Importa salientar, ainda, que as ONGs, ao realizarem trabalhos voltados especialmente às populações em condições de vulnerabilidade social, tendo como finalidade o empoderamento dos beneficiários, vão ao encontro do que determina a LOAS, tendo sua atuação pautada pelos princípios da política de assistência social (Costa, 2005).

Assim, essas instituições são de grande importância para o Estado, por auxiliarem na redução dos problemas sociais, como desemprego, dificuldade de acesso à educação, cultura e políticas públicas. Ainda, as ONGs minimizam, significativamente, os índices de desigualdade social, na medida em que atuam tanto na defesa como na garantia de direitos (Rodrigues, 1998). 
São pouco frequentes estudos que avaliam os impactos de ações sociais de organizações do terceiro setor, especialmente através da percepção dos beneficiários. Um exemplo é a própria organização em estudo, a qual, em 30 anos de trabalho junto à comunidade, nunca havia realizado avaliação de suas ações. Dessa forma, considerando que as pesquisas com ênfase nessa temática são relativamente novas em meio à comunidade científica e dada a importância das ONGs para o desenvolvimento econômico e social do país devido à sua crescente expansão, o objetivo do presente artigo é verificar, através da percepção das comunidades beneficiárias, o impacto social das ações promovidas por uma organização sem fins lucrativos, classificada como ONG, que atua em três estados brasileiros - Rio Grande do Sul (RS), Mato Grosso (MT) e Rondônia (RO).

Como objetivos secundários, esta investigação propôs-se a identificar os motivos de participação das comunidades nas ações desenvolvidas e a avaliação que fazem dessas, ainda, os aspectos a serem melhorados em cada localidade e a realização de um comparativo entre os três estados, do impacto social das ações desenvolvidas pela ONG. Foram buscas deste estudo, também, conhecer o alinhamento das ações para a melhoria da qualidade no atendimento das demandas sociais que constituem o foco do trabalho dessas entidades.

Considerando tais perspectivas, apresenta-se este constructo organizado em seis partes essenciais. Essa primeira que contextualiza a pesquisa, apresentando seus objetivos e justificativas, seguida de uma descrição teórica sobre impacto social e, na sequência, sobre o terceiro setor e assistência social. A seguir, aponta-se o procedimento metodológico adotado para o estudo e, de imediato, os resultados e discussões para, após, concluirse o trabalho de acordo com os objetivos propostos.

\section{Impacto Social}

Impacto social é conceituado como uma mudança significativa e de longo prazo na vida das pessoas, sendo consequência de determinada ação ou de uma série delas (Barrow, 2002; Ebrahim \& Rangan, 2014). Tal impacto pode representar tanto progresso significativo quanto degradação do bem-estar de uma população (Goldman \& Baum, 2000), pois a mudança nas práticas sociais conduz à transformação social (Howadt, Domanski, \& Kaletka, 2016).
O impacto social tem sido igualmente compreendido como mudança social no ambiente humano, resultante de várias ações ou eventos sociais (Serje, 2017). Esse mesmo autor destaca que o entendimento do impacto decorre das mudanças causadas por intervenções planejadas, no contexto em que ele é produzido. Serje (2017) faz, ainda, alusão ao sentido etimológico da palavra impacto, cuja origem latina impingere significa força, unidade ou impulso contra alguma coisa, resultando literalmente em colisão.

O impacto social é percebido quando certas ações influenciam a comunidade, beneficiando-a e provendo ações segundo suas necessidades (Coad, Campbel, Miles, \& Humphries, 2008; Karki, 2013). O impacto social advém, portanto, de experiências vivenciadas por pessoas, como indivíduos ou como grupo, quer em sentido físico, quer em termos cognitivos (Vanclay, 2002; Jones, McGinlay, \& Dimitrapoulos, 2017).

O impacto social influencia potencialmente a qualidade de vida das pessoas beneficiadas por alguma ação, seja ela qual for (Yuruk, Akyol, \& Simsek, 2017). As ações podem contribuir para a redução dos níveis de pobreza de pessoas e comunidades, fortalecendo a segurança, oferecendo oportunidades, propiciando capacitações (Canavire-Bacarreza \& Hanauer, 2012; Clements, Suon, Wilkie, \& Milner-Gulland, 2014; Ferraro \& Hanauer, 2014), dentre outras consequências.

O impacto social também é entendido como algo que tem familiaridade ou alguma ligação com um projeto que afeta ou diz respeito aos stakeholders (grupos de interesse), desde que seja valorizado e importante para um grupo específico (Vanclay, With, Aucamp, \& Franks, 2015). Ainda de acordo com os citados autores, o projeto deve, pois, abordar tudo o que é relevante para as pessoas e para seu modo de vida e possibilitar a compreensão de como ele vai afetar o que é importante para seus stakeholders.

Nessa direção, de acordo com Vanclay (2003), são consideradas impacto social mudanças em um ou mais dos seguintes contextos:

a) modo de vida das pessoas: como vivem, trabalham, jogam e interagem umas com as outras, no cotidiano;

b) cultura: crenças, costumes, valores, língua ou dialeto;

c) comunidade: harmonia, estabilidade, caráter, serviços, alojamentos; 
d) sistemas políticos: a dimensão na qual as pessoas são capazes de participar das decisões que afetam suas vidas, o grau de democratização que está ocorrendo, os recursos previstos para o efeito;

e) ambiente: a qualidade do ar e da água, disponibilidade e qualidade dos alimentos;

f) nível de perigos ou riscos: poeira e ruído a que estão expostos os indivíduos, adequação do saneamento, características físicas segurança, acesso e controle sobre os recursos;

g) saúde e bem-estar: compreendendo que a saúde é um estado de bem-estar físico, mental, social e espiritual e não mera ausência de doença ou enfermidade;

h) direitos pessoais e de propriedade: especialmente quando as pessoas estão economicamente afetadas ou têm experiência de desvantagens pessoais, que podem incluir a violação de seus direitos civis;

i) medos e aspirações: percepções sobre sua segurança, medos sobre o futuro de sua comunidade e aspirações para o próprio futuro e o de seus filhos.

A partir dessas definições de impacto social emerge o conceito de avaliação do impacto social. Uma das mais atualizadas é expressa pela International Association for Impact Assessment (IAIA) - Associação Internacional para Avaliação de Impacto. Essa o define como processo de análise para monitorar e gerenciar as consequências sociais planejadas e não planejadas, tanto positivas quanto negativas. As intervenções planejadas (políticas, programas, planos, projetos) são quaisquer processos de mudança social invocados por essas intervenções, que afetam ou preocupam as pessoas, direta ou indiretamente (Vanclay et al., 2015). As intervenções não planejadas, por sua vez, decorrem das primeiras, são as suas consequências, não possuindo previsibilidade.

A avaliação de impacto social significa, na expressão dada por Roche (2000, p.37), "a análise sistemática das mudanças duradouras ou significativas - positivas ou negativas, planejadas ou não - nas vidas das pessoas e ocasionadas por determinada ação ou série de ações". Conforme tais concepções, a avaliação de impacto busca levar em conta as pessoas beneficiadas, diretamente envolvidas nas relações das mudanças provocadas, considerando valores e atitudes, preocupações, percepção em relação à gestão e ao uso de recursos, capacidade de avaliar, responder, aceitar e aspirar mudanças (Roche, 2000; Moura, 2008).

Assim compreendida, a avaliação do impacto social integra os processos da gestão das questões sociais dos diversos projetos, considerando que, em cada fase de seu desenvolvimento, é preciso haver um processo interativo. Nesse, as pessoas precisam ter o direito de se envolverem na tomada de decisão sobre as intervenções planejadas, que irão afetar ou influenciar suas vidas (Vanclay et al., 2015).

De modo geral, a avaliação de impacto social tem uma ligação muito forte com suas consequências para as pessoas participantes das ações públicas ou privadas, as quais influenciam na maneira como tais indivíduos vivem, se relacionam, trabalham, se divertem, se organizam e planejam como se sustentar e como suprir suas necessidades mais emergentes (Burdge et al., 1995; Jones et al., 2017).

Nessa direção a avaliação de impacto social tem especial relevância no terceiro setor, onde figuram atuantes as organizações sem fins lucrativos com forte impacto na vida social de indivíduos e grupos é sobre esse contexto que se descreve a seguir.

\section{Terceiro Setor e Assistência Social}

O terceiro setor constitui um segmento não lucrativo, cuja origem está em um modelo de sociedade que se reconhece como veículo de protestos contra as elites dominantes, as quais atuam tanto na esfera política como na econômica. Esse setor apresenta-se como o reflexo da impotência do estado e do mercado em responder às necessidades democráticas dos cidadãos mais vulneráveis (Assumpção \& Campos, 2011; Tavares Neto \& Fernandes, 2010).

O terceiro setor é formado por entes privados que, dentre seus objetivos sociais, não visam ao lucro (Gimenes \& Leonardo, 2009; Salamon \& Anheier,1996; Tude \& Rodrigues, 2008). Esses entes não estão vinculados à organização centralizada ou descentralizada da administração pública e prestam serviços em áreas de relevante interesse social e público (Rocha, 2003; Rodrigues, 1998). Assim, é composto por organizações regidas pelo Código Civil Brasileiro, de acordo com a Lei 10.406/02, com os acréscimos formulados pelas Leis 10.825/03 e 
11.127/05, reconhecidas como pessoas jurídicas de direito privado, denominadas associações, fundações, organizações religiosas e partidos políticos (Lei ${ }^{\circ}$ 13.019, 2014).

O terceiro setor compreende, portanto, entidades sem fins lucrativos que desenvolvem ações sociais e recebe diferentes denominações como setor social, setor sem fins lucrativos, setor de promoção social, economia social, setor voluntário (Olak \& Nascimento, 2009). Suas principais particularidades são a filantropia, os investimentos em programas e projetos sociais e a diversidade das entidades que o compõem (Britto \& Bittencourt, 2008).

Essas organizações atuam nas mais diversas áreas como as de saúde, educação e assistência social (Duarte, Cavalcante, \& Marques, 2017; Vila Nova, 2004). Aquelas que têm por finalidade ações de assistência social estão vinculadas à política pública de assistência social, por isso não podem perder sua característica social que as diferenciam de outros setores da sociedade (Dess, 1998; Ryan, 1999; Tude \& Rodrigues, 2008; Yoffe, 2003). A assistência social, como ação política, distingue-se pela intervenção social e pela interação com os interesses econômicos da classe dominante, comprovando, por meio de ações, sua forma de interferir na realidade da sociedade brasileira (Sousa, Nunes, Sousa, Sousa, \& Alves 2013).

O público-alvo da assistência social compreende qualquer pessoa que dela necessitar, devido à sua vulnerabilidade e ao risco social (Cardoso Junior \& Jaccoud, 2005; Constituição da república federativa do Brasil, 1998; Olivindo, 2015). Tais pessoas requerem o amparo do Estado, o qual tem, dentre seus deveres, a proteção comum a todos que lutam contra as causas das vulnerabilidades, sobretudo contra a pobreza e a marginalização. O Estado tem, ainda, o dever de promover a integração social dos desfavorecidos (Olivindo, 2015).

Desde a promulgação da Constituição de 1988, houve maior cuidado da legislação quanto à ampliação dos direitos de cidadania e dos princípios de descentralização na promoção de políticas sociais (Mañas \& Medeiros, 2012). Segundo os autores citados, isso gerou avanço nos programas assistenciais voltados para as populações em situação de risco e vulnerabilidades sociais, com o propósito de assegurar condições suficientes para atender às necessidades básicas de todo o contingente de pessoas e famílias em condições vulneráveis.
As organizações sem fins lucrativos, com foco na assistência social, seguem as diretrizes do Sistema Único de Assistência Social, como já citada, a Lei 8.742/93 (LOAS) e as demais legislações complementares, objetivando a proteção social. Essa visa à garantia da vida, à redução de danos e à prevenção da incidência de riscos, pelo desenvolvimento de uma intervenção social planejada, que se materializa no estímulo e na orientação dos usuários na construção e reconstrução de suas histórias individuais e coletivas, na família e no território onde vivem (Lei no ${ }^{\circ}$ 8.742, 1993).

O terceiro setor com seus diversos arranjos (dentre esses as ONGs), caracteriza-se pela criação de situações de convivência que incentivem a realização de diálogos e fazeres que constituam meios para o enfrentamento de vulnerabilidades e para a construção de alternativas em prol de uma progressiva transformação social (Lei no 8.742, 1993; Salinas, Cabral, \& Iranzo, 2015). Isso significa considerar as pessoas não apenas como beneficiárias de uma ação, mas também como agentes de mudança, capazes de desenvolver habilidades e realizar um desenvolvimento interno que contagie o meio externo (Guimarães, 2016; Sen, 2000; Vieira, Andrade, Ckagnazaroff, Machado, Cheib, \& Abreu, 2009). Por assim compreender, no tomo seguinte expõe-se os procedimentos metodológicos utilizados para compreender os indivíduos afetados e as transformações sociais ocorridas a partir de ações de uma ONG em três estados brasileiros.

\section{Procedimento metodológico}

Este estudo caracteriza-se como de abordagem quantitativa, descritivo e de cunho transversal. A amostra foi composta por 322 participantes, com idade mínima de 18 anos, conhecedores ou integrantes de atividades de ação social desenvolvidas por uma organização sem fins lucrativos, contatados nos municípios de Passo Fundo-RS ( $\mathrm{n}=106$ ), Barra do Garça-MT ( $n=110)$ e Mutum Paraná-RO ( $\mathrm{n}=106)$, selecionados em centros sociais, em um plano de amostragem não probabilístico, por conveniência.

A coleta de dados foi realizada por meio de formulário, adotado por possibilitar a participação de analfabetos. Esse compôs-se de 32 questões, dividido em quatro partes: (i) caracterização sociodemográfica dos participantes; (ii) grau de conhecimento e participação nas ações sociais da organização; (iii) avaliação das ações; (iv) sugestões para futuras ações de interesse 
da comunidade. O instrumento foi composto por questões que exigiam respostas abertas, fechadas e múltiplas, sendo as mesmas para os três estados. Houve, no entanto, no instrumento de coleta de dados aplicados em RO, o acréscimo de um item - 'avaliação geral' -, porque o período da pesquisa coincidiu com o da avaliação anual das ações da organização objeto deste estudo.

A coleta de dados se deu, em cada um dos locais, por uma equipe composta por profissionais que trabalham na organização, além de pessoas voluntárias da comunidade, previamente treinadas para a aplicação dos formulários. Os pesquisadores deslocaram-se até os centros sociais comunitários, lugares de maior circulação da comunidade e de beneficiários das ações da Organização, por um período de 30 dias, para a aplicação dos formulários. Nesses locais, as pessoas recebiam informações sobre a natureza e os propósitos do estudo e eram convidadas a responder a pesquisa. Ao concordarem em participar, assinavam o Termo de Consentimento Livre e Esclarecido. $\mathrm{O}$ projeto de pesquisa relativo a este estudo foi previamente submetido à apreciação de um Comitê Ética em de Pesquisa e aprovado sob o CAAE 45252615.2.0000.5319 e comprovante 044721/2015.

Utilizou-se a estatística descritiva para a análise das variáveis relativas ao perfil sociodemográfico dos participantes do estudo. Para avaliar comparativamente as idades dos participantes, recorreu-se ao diagrama de extremos e quartis - Box-plot (a mediana, o $1^{\circ}(\mathrm{Q} 1)$ e o $3^{\circ}(\mathrm{Q} 3)$ quartis, os valores mínimos e máximos, extremos e outliers). O teste de Quiquadrado de independência foi usado para verificar se a decisão de participar em atividades promovidas pela organização, a avaliação do trabalho realizado, as sugestões oferecidas pelos beneficiários e a proporção de participantes nos serviços oferecidos dependem do estado onde os dados foram coletados. Foi considerada uma probabilidade de erro do tipo I $(\alpha)$ de 0,05 para as análises efetuadas.

As análises estatísticas foram realizadas com os procedimentos implementados no software de análise estatística SPSS Statistics (v.23; IBM SPSS, Chicago, IL.), como descrito em Field (2013) e Marôco (2014). As informações coletadas das perguntas abertas do questionário foram analisadas por meio da técnica de análise de conteúdo, operacionalizada com o auxílio do software MAXQDA, versão 10.0.

\section{Resultados e Discussão}

Dos 322 participantes do estudo, 106 pertencem à comunidade atendida pela organização no RS; 110, à unidade do MT; 106, à unidade de RO, sendo que o perfil sociodemográfico em relação ao sexo, faixa etária, escolaridade, estado civil, ocupação e renda, podem ser observados à Tabela 1 .

Tabela 1. Perfil sociodemográfico dos participantes do estudo correspondente aos três estados de atuação da organização

\begin{tabular}{|c|c|c|c|}
\hline \multicolumn{2}{|l|}{ Características } & \multirow{2}{*}{\begin{tabular}{|c|}
$n$ \\
141
\end{tabular}} & \multirow{2}{*}{$\begin{array}{c}\% \\
43,8\end{array}$} \\
\hline Sexo & Masculino & & \\
\hline & Feminino & 181 & 56,2 \\
\hline \multirow{6}{*}{ Faixa etária } & Até 20 anos & 15 & 4,7 \\
\hline & 21 a 30 anos & 70 & 21,8 \\
\hline & 31 a 40 anos & 85 & 26,5 \\
\hline & 41 a 50 anos & 72 & 22,4 \\
\hline & 51 a 60 anos & 52 & 16,2 \\
\hline & Acima de 60 anos & 27 & 8,4 \\
\hline \multirow{13}{*}{ Escolaridade } & Analfabeto & 6 & 1,9 \\
\hline & Fundamental & 46 & 14,3 \\
\hline & incompleto & 16 & 5,0 \\
\hline & Fundamental & 51 & 15,8 \\
\hline & completo & 87 & 27,0 \\
\hline & Ensino médio & 52 & 16,1 \\
\hline & incompleto & 41 & 12,7 \\
\hline & Ensino médio & 8 & 2,5 \\
\hline & completo & 15 & 4,7 \\
\hline & $\begin{array}{l}\text { Ensino superior } \\
\text { incompleto }\end{array}$ & & \\
\hline & $\begin{array}{l}\text { Ensino superior } \\
\text { completo }\end{array}$ & & \\
\hline & $\begin{array}{l}\text { Pós-graduação } \\
\text { incompleto }\end{array}$ & & \\
\hline & $\begin{array}{l}\text { Pós-graduação } \\
\text { completo }\end{array}$ & & \\
\hline \multirow{6}{*}{ Estado civil } & Solteiro & 67 & 20,8 \\
\hline & Casado & 167 & 51,9 \\
\hline & Separado & 13 & 4,0 \\
\hline & Viúvo & 19 & 5,9 \\
\hline & União Estável & 54 & 16,8 \\
\hline & Outro & 2 & 0,6 \\
\hline \multirow{11}{*}{ Ocupação } & Empregado de & 72 & 22,4 \\
\hline & empresa privada & 59 & 18,3 \\
\hline & Funcionário público & 11 & 3,4 \\
\hline & Empresário & 8 & 2,5 \\
\hline & Profissional liberal & 30 & 9,3 \\
\hline & Autônomo & 22 & 6,8 \\
\hline & Estudante/Estagiário & 24 & 7,5 \\
\hline & Aposentado & 70 & 21,7 \\
\hline & Do lar & 18 & 5,6 \\
\hline & Desempregado & 8 & 2,5 \\
\hline & Outro & & \\
\hline
\end{tabular}




\begin{tabular}{llll}
\hline & & & \\
\hline & Até 1 salário mínimo & 73 & 22,7 \\
De 1 a 2 salários & 95 & 29,5 \\
Renda & mínimos & 60 & 18,6 \\
& De 2 a 3 salários & 30 & 9,3 \\
& mínimos & 16 & 5,0 \\
& De 3 a 4 salários & 15 & 4,7 \\
& mínimos & 10 & 3,1 \\
& De 4 a 5 salários & 15 & 4,7 \\
& mínimos & 8 & 2,5 \\
& De 5 a 6 salários & & \\
& mínimos & & \\
& De 6 a 7 salários & \\
& mínimos & \\
& Acima de 7 salários & \\
& mínimos & \\
& Sem renda declarada & \\
&
\end{tabular}

Fonte: Autores (2017).

O perfil geral da amostra dos três estados, como apresenta-se na Tabela 1 , revela que a maioria dos participantes é mulher $(56,2 \%)$ e o predomínio da faixa etária está entre 31 a 50 anos (48,9\%). Quanto à escolaridade, a maior parte da amostra possui ensino médio completo (27\%), e estado civil de casados $(51,9 \%)$. No que tange à ocupação, a maior parte da amostra exerce a função de empregado de empresa $(22,4 \%)$, com renda mensal média é de um a dois salários mínimos (29,5\%).

Ainda dentro do traço sociodemográfico, especificando-se as realidades por estado, observase na Figura1 a condição de idade dos participantes da amostra considerada. Nela, os traços horizontais extremos indicam a menor e a maior idade dos participantes do estudo. O traço horizontal, no interior da caixa, indica a idade que separa o grupo em duas partes iguais, ou seja, $50 \%$ das pessoas têm idade acima e 50\% abaixo dessa faixa etária. A altura da caixa fornece os limites de idade dentro dos quais se encontram $50 \%$ dos participantes. Tomando-se como exemplo os participantes da pesquisa no RS, observase que a menor e a maior idade são 18 e 79 anos, respectivamente. Observa-se também que metade tem idade superior a, aproximadamente, 40 anos e a outra metade, abaixo. A maior altura da caixa para as idades dos participantes está em RO, indicativo de sua maior heterogeneidade etária. Nesse estado, a menor e a maior idade são 19 e 84 anos, respectivamente. Em MT, elas são 17 e 78 anos, respectivamente (Figura 1).
Figura 1. Box-plot das idades dos participantes segundo o estado em que os dados foram coletados

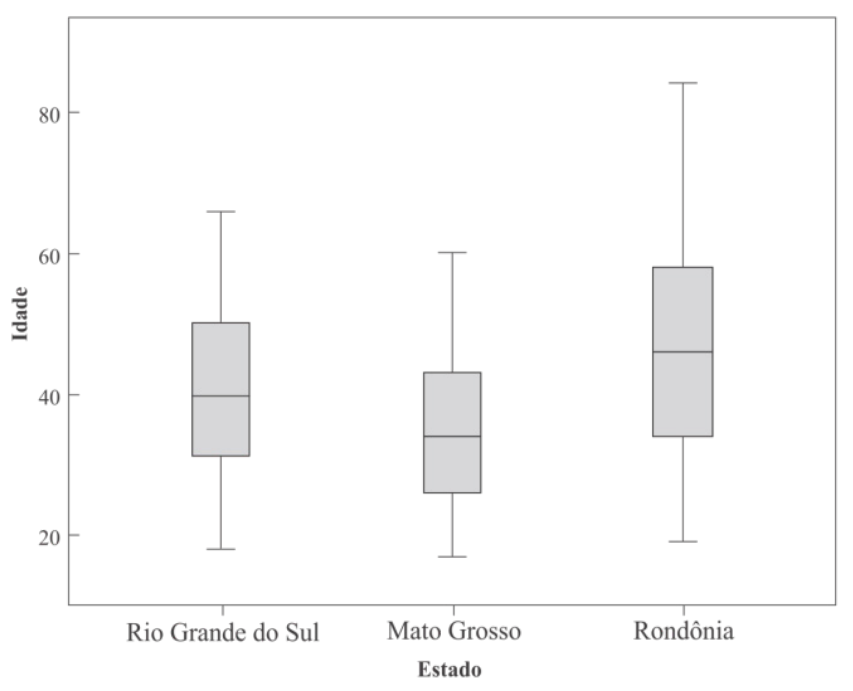

Fonte: Autores (2017).

Em síntese, pode-se dizer que no estado do MT os beneficiários são mais jovens, em contrapartida, no estado de RO mais velhos. Para além do perfil sociodemográfico, buscou-se investigar os motivos apontados pela amostra para a participação nas ações sociais promovidas pela organização, nos três estados, indicando-lhes as seguintes possibilidades: acolhida, recomendação de amigos, recomendação de familiares, tipo de ações desenvolvidas.

Nessa direção, e conforme mostrado na Figura 2, a acolhida é o principal motivo que leva à participação dos usuários - item mais bem avaliado pelos participantes e que foi significativamente maior em RO $\left(\chi^{2}=\right.$ 26,115, $\mathrm{gl}=8, \mathrm{n}=171, P<0,05)$, quando comparado à proporção indicada pelos participantes nos outros estados que não difere entre si $(P>0,05)$ (Figura 2). Quando considerado o total de respondentes nos três estados, a acolhida e o tipo de ação desenvolvida pela organização perfazem $79,9 \%$ dos motivos da amostra analisada para dela participar.

Se analisado separadamente, no RS, $43,4 \%$ dos participantes evidenciaram a acolhida como principal razão para participação nas ações, seguida do tipo de ação desenvolvida (34\%). No MT, 46,4\% revelaram a acolhida como principal motivo e $22,7 \%$ as ações desenvolvidas. Em RO, por sua vez, a maioria dos entrevistados também destacou a acolhida (69,8\%) e 20,8\%, o tipo de ação desenvolvida (Figura 2). 
Figura 2. Distribuição percentual dos motivos apontados para participação nas ações sociais promovidas pela organização, nos três estados

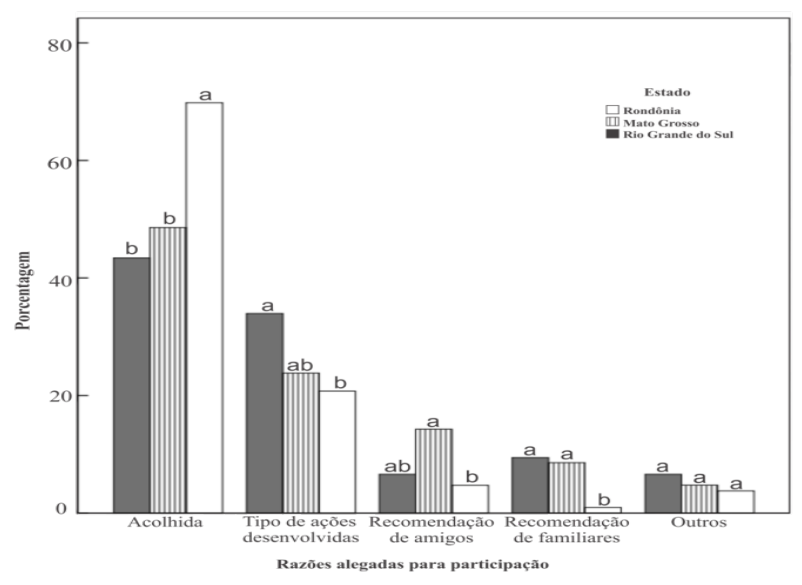

Fonte: Autores (2017).

Nota. Cada letra de subscrito indica um subconjunto de Estado categorias cujas proporções da coluna não se diferem significativamente umas das outras no nível 0,05.

Após revelarem os motivos de participação, os participantes avaliaram o trabalho realizado pela organização, nos três estados, utilizando de uma escala (excelente, muito bom, bom, razoável e muito ruim). Assim, de modo geral, a avaliação do trabalho desenvolvido foi positiva, não só pelas ações empreendidas, mas, também, pela estrutura da ONG, que compreende as instalações e o espaço físico em que as ações são realizadas (Figura 3).

Figura 3. Distribuição percentual das avaliações que os participantes fizeram do trabalho

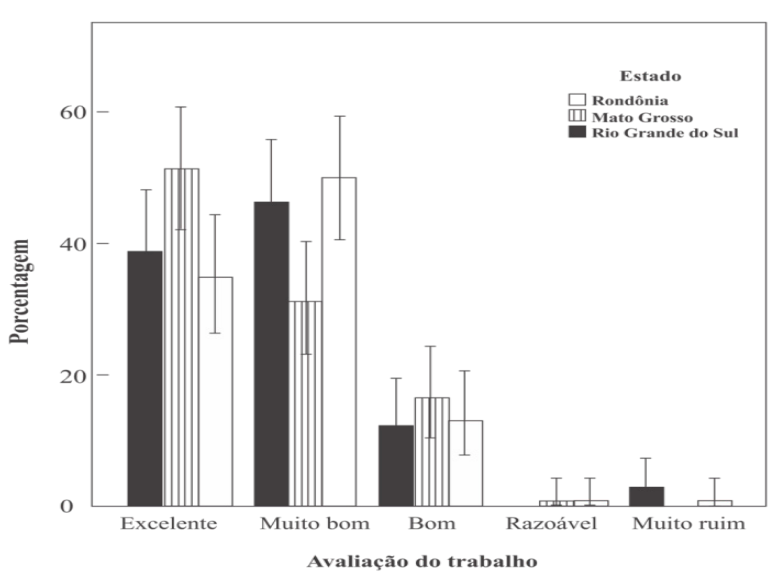

Fonte: Autores (2017).
Especificando-se a avaliação por estado (Figura 3), observa-se que no RS 46,2\% dos respondentes avaliam o trabalho como muito bom e $42,5 \%$ consideram a estrutura adequada, classificando-a, também, como muito boa. Em RO, 50,0\% qualificam o trabalho como muito bom e $41,4 \%$ avaliam a estrutura como muito boa. No MT, trabalho e estrutura são classificados, pela maioria, como excelentes. Depreende-se dessas avaliações, conforme a Figura 3, que o impacto causado na vida das pessoas pela organização vai além da pretensão de suas ações, estendendo-se ao acolhimento oferecido quando do uso dos espaços, que se mostraram adequados para o desenvolvimento das atividades.

Seguindo-se no objetivo do estudo, buscou-se colher sugestões de melhorias apontadas pelos participantes para qualificar os serviços da organização em pauta nos três estados. A divulgação das ações e o acréscimo de parcerias públicas e privadas foram as sugestões dadas pela maioria da amostra, mais de 50\%, representando, assim, as melhorias que a organização deve implementar (Figura 4).

Figura 4. Distribuição percentual das sugestões de melhoria apontadas pelos participantes

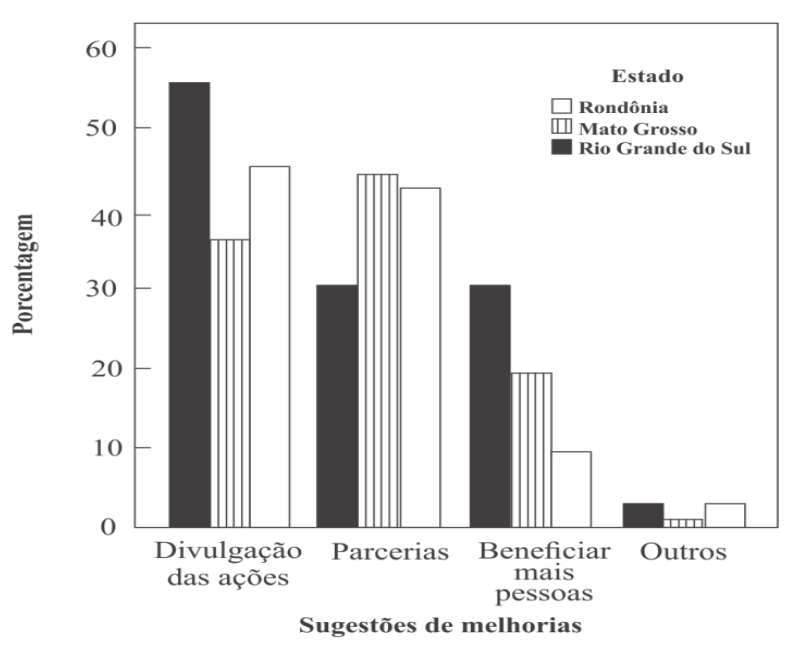

Fonte: Autores (2017).

Ao serem perguntados sobre ter recebido algum tipo de benefício da instituição (roupas, alimentos, emprego, serviços, atendimento em saúde, outros), obteve-se como resposta que $91 \%$ no RS, $99 \%$ no MT e $81 \%$ em RO estão sendo atendido pelas ações promovidas pela organização. Dos atendidos, 68,9\%, 
no RS; 70\%, no MT; 92,5\%, em RO foram beneficiados com roupas, alimentos, serviços, encaminhamentos referentes à saúde, dentre outros. Ainda por meio de perguntas fechadas se buscou compreender o índice de atendimento da organização, bem como em quais dos serviços oferecidos (educação infantil/ visita domiciliar, orientação social, psicológica e pastoral, formação e capacitação, outros) nos três estados, a amostra mais participa. A distribuição mostrada na Figura 5 indica que a participação nos serviços oferecidos pela organização, no RS, é maior em projetos sociais (45,1\%); no MT, na educação infantil (31,6\%); em RO, na formação e capacitação de lideranças $(27 \%)$.

Figura 5. Comparação da participação nos serviços oferecidos pela organização

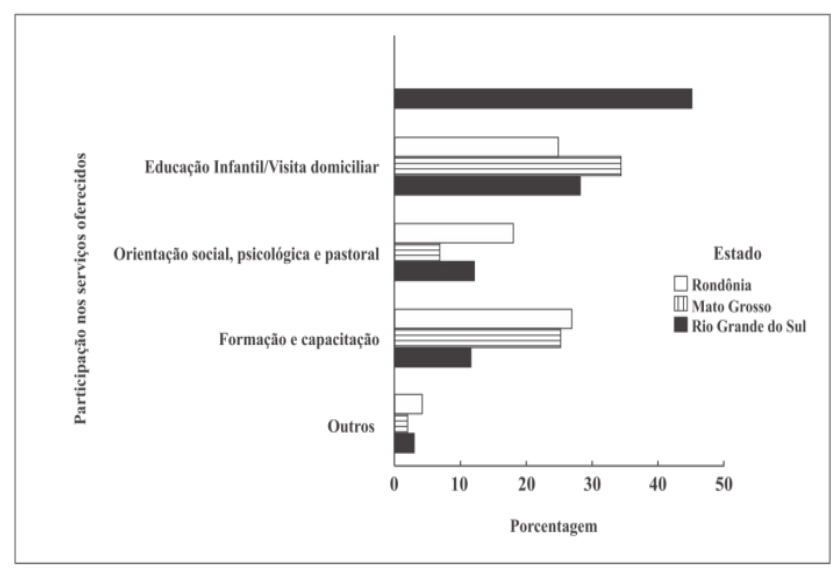

Fonte: Autores (2017).

Em suma, as análises estatísticas realizadas a partir do conjunto de questões ora expresso permitem inferir que a participação expressiva dos entrevistados nas ações sociais da organização tem como principais motivos a acolhida e o tipo de ação desenvolvida. De modo geral, a avaliação do trabalho desenvolvido e a estrutura da organização foi considerada pela maioria da amostra como positiva, sendo que como sugestão de melhorias destacou-se a demanda por melhor divulgação das ações e aumento nas parcerias da instituição com órgãos públicos e privados. Ainda, revelou-se a participação da maior parte da amostra está sendo atendida pelas ações promovidas pela organização, no entanto, para cada estado essa participação mostrou-se de modo diferente: no RS maior em projetos sociais, no MT, na educação infantil, em RO na formação e capacitação de lideranças.
Tais resultados coadunam com as respostas obtidas por meio das perguntas fechadas. Primeiramente, evidenciando a coerência entre as necessidades da comunidade e as ações sociais da organização, as quais atingem as principais demandas: "vêm ao encontro das necessidades das famílias" (Participante 55/RS), "ajudam as mulheres terem uma renda e as crianças e adolescentes a serem abertas para enfrentarem e superarem com coragem os desafios da vida, a partir das oficinas de convivência e fortalecimento de vínculos que participam" (Participante 83/RS). Destaca-se, ainda, a importância do atendimento humanizado refletido na acolhida, ou seja, no primeiro contato do usuário com a organização. Segundo Aranha, Silva e Silva (2011), esse tipo de atendimento se caracteriza pela disposição dos serviços às demandas locais, assegurando um espaço de escuta, atenção e bem-estar social.

Em relação à avaliação das ações realizadas pela organização, os participantes reconhecem o trabalho e os benefícios que proporciona à comunidade, tendo sido avaliados, nos três estados, de forma muito positiva.

\begin{abstract}
Se não fosse este trabalho realizado aqui no nosso bairro pela Organização, não nos teríamos tornado protagonistas, pois nosso bairro antes da vinda da Organização era muito discriminado, não tinha luz e nem água, e o trabalho frutuoso deu resultado positivo nas famílias, por meio da educação infantil e dos projetos sociais. Fizeram o bairro se desenvolver e estruturarse, todos fomos beneficiados com as ações que transformaram nossas vidas (Participante 62/MT).
\end{abstract}

Quando a Organização veio para o MT, escolheu construir no meio de nós a sua estrutura. Éramos excluídos da cidade e todo mundo tinha medo de vir aqui no nosso bairro porque tinha muita morte, era muito agressivo. A presença e o trabalho da Organização mudaram a nossa vida e o modo como as pessoas nos veem hoje. Sou grato pela existência da Organização e por gostarem de nós (Participante 64/MT)

O resultado expresso pelos participantes corrobora o estudo de Gambardella (2014), o qual salienta que 
o processo avaliativo assegura que os recursos sejam investidos de forma eficiente, atendendo, com maior qualidade, as demandas sociais.

Se hoje sou o que sou, devo a todos os benefícios que recebi da Organização, da formação e capacitação que tive oportunidade de participar. Apostaram em mim e hoje reconheço com gratidão todo trabalho incansável dedicado a mim e às pessoas que participavam comigo, pela possibilidade de mudar de vida e liberdade de escolha. O que aprendi levo para a minha vida (Participante 61/MT).

Sob outra perspectiva, quando se considera a teoria da gestão social (Cabral, 2011), as organizações sem fins lucrativos, ao produzirem benefícios para a coletividade, na forma de bens de consumo ou de ações sociais, também são reprodutoras de valores sociais. A avaliação de impacto deve, portanto, considerar a relação entre os valores transmitidos pela organização e os benefícios gerados (Cabral, 2011; Yuruk et al., 2017).

Quando questionados os aspectos em que a Organização deveria investir no intuito de buscar melhorias, destacaram-se a divulgação das ações e o acréscimo de parcerias. O que, segundo Austin (2001) e Monte e Carvalho (2005), tem intenção de proporcionar a consecução da missão da cada uma das partes envolvidas na realização de suas finalidades, podendo ser com empresas locais ou com órgãos municipais, estaduais e federais, dentre outros. Dado ser extenso e longitudinal o trabalho da Organização, de modo particular em RO, ressalta-se a fala de um dos participantes:

Sugiro que pensem ações para crianças e jovens que mais necessitam e são muito pobres, moram do lado do canalão e não têm opção de vida, porque ali é o maior local de tráfico de drogas e ver isso dói, ver as crianças e adolescentes naquela situação. Muitas delas já participam nas oficinas, mas a minha expectativa é que se possa atingir mais crianças e adolescentes e tentar ajudá-las (Participante 100/RO).

As instituições sem fins lucrativos utilizam, prioritariamente, o marketing para atrair recursos, conforme estudo de Shiraishi e Campomar (2011). O marketing é uma ferramenta importante tanto na construção da imagem da organização, quanto na divulgação de ações, benefícios e resultados alcançados, assim como, na atração de novos investimentos (Santos \& Silva, 2012; Serje, 2017). As parcerias não se limitam apenas àquelas que repassam recursos financeiros, mas abrangem também instituições municipais de saúde e educação, famílias, igrejas, associações, que possam contribuir com o trabalho a ser realizado e suprir as necessidades emergentes (Maciel \& Castilhos, 2012; Jones et al., 2017).

Com relação ao impacto social das ações, a maioria dos entrevistados beneficia-se dos serviços prestados pela Organização, os quais se delineiam como projetos sociais, serviços de formação, de capacitação, de educação, de orientação social e psicológica, dentre outras ações como a doação de roupas e alimentos.

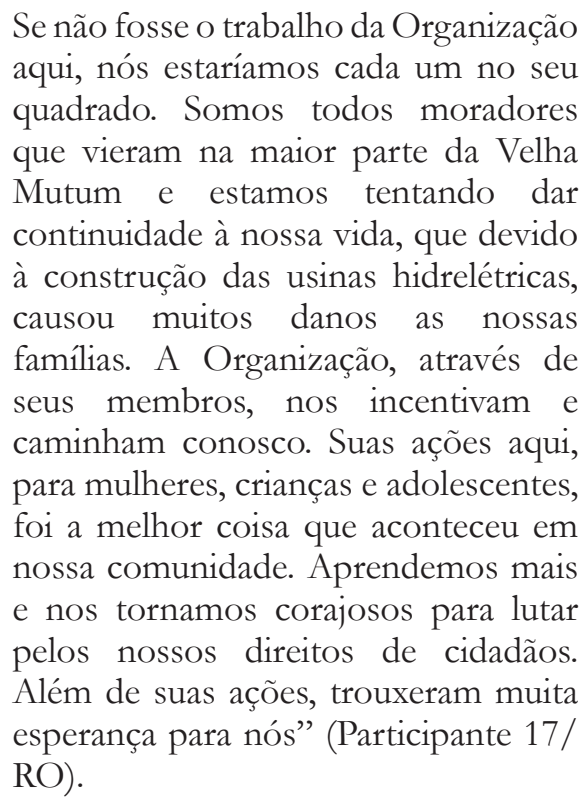

Tal excerto ressalta a importância que a organização representa para as comunidades locais, atuando na garantia de direitos e na prestação de serviços de proteção social, o que contribui para a formação da cidadania e a redução da desigualdade social (Maciel \& Castilhos, 2012; Olivindo, 2015).

Verifica-se que organizações com ações de caráter assistencialista nas áreas social, de saúde, capacitação e educação são mais prevalentes em países que estão em processo de desenvolvimento do que naqueles desenvolvidos (Vila Nova, 2004; Costa, Silva, \& Bonan 2011; Duarte et al., 2017), devido à atuação dessas instituições em setores negligenciados pelo Estado. 
Nessa perspectiva, as organizações do terceiro setor representam um agente indispensável no processo de constituição da cidadania e de defesa dos interesses sociais, assim como na efetividade da democracia, uma vez que, ao trabalhar em prol do empoderamento das pessoas, contribuem ativamente para o desenvolvimento social (Tavares Neto \& Fernandes, 2010; Sousa et al., 2013;).

\section{Considerações Finais}

O presente estudo teve como foco verificar o impacto social das ações promovidas por uma organização, em três estados brasileiros - RS, MT e RO -, conforme a percepção das comunidades beneficiárias. Tais ações desenvolvidas em cada estado, buscam atender as necessidades das comunidades, com foco principal na assistência social, sendo ofertadas possibilidades de convivência, de fortalecimento de vínculos, de geração de emprego e renda, por meio de oficinas socioeducativas. No MT, há oferta também da educação infantil. Em RO são desenvolvidas ações de formação e capacitação de lideranças comunitárias.

Assim, por meio de aplicação de formulários a uma amostra de 322 participantes usuários dos serviços da referida instituição, foi possível identificar que nos três estados essas ações são relevantes por estarem de acordo com as necessidades locais; por serem permanentes, planejadas e continuadas; por favorecerem o desenvolvimento integral da pessoa, em todas as suas dimensões; por contribuírem para a garantia e a defesa dos direitos individuais e coletivos. Elas têm impacto social relevante, ainda, por estarem de acordo com as necessidades de cada local e por favorecerem oportunidades pontuais pela valorização das capacidades individuais, em uma construção coletiva, com oportunidades de escolha que propiciam nova realidade de vida, conforme destacado por Barrow (2002), Ebrahim e Rangan (2014) e Serje (2017).

A importância de divulgar as ações desenvolvidas pela organização e de aumentar o número de parcerias foram, dentre outros, dois aspectos que emergiram do estudo que, segundo os participantes, precisam ser melhorados em cada localidade, nos três estados. Quanto mais forem divulgadas as ações, mais pessoas tomarão conhecimento de seus benefícios e mais recursos poderão ser captados por meio de stakeholders - grupos de interesse para a organização - da própria comunidade e se poderá obter a contribuição de novos e mais desses, sobretudo para a mobilização de recursos financeiros.

Os dados e as informações coletadas neste estudo também evidenciam que as ações desenvolvidas pela organização se adequam à realidade de cada local e são desenvolvidas conforme as necessidades das famílias beneficiadas, tais resultados vem ao encontro do que Burdge et al., (1995) e Jones (2017) destacam no sentido de que quando uma organização tem planejamento, essa consegue suprir suas necessidades mais emergentes. Se comparados, nos três locais, existem projetos sociais com foco no serviço de convivência e fortalecimento de vínculos. No MT, além dessas ações, há o programa de educação infantil integral, que atende, de forma gratuita, crianças do bairro onde está sediada a organização e do seu entorno.

O impacto social acontece, nesses espaços, quando as ações são desenvolvidas considerando-se as necessidades locais e a possibilidade de oportunidades para melhoria de vida, conforme destacado por Yuruk et al. (2017), que, por seu turno, favorecem a formação de pessoas protagonistas e de cidadãos conscientes de seus direitos e deveres, agentes da própria transformação.

Assim considerado, o presente estudo alcança seu objetivo principal e secundários a partir de dois pontos. Primeiro, no que tange aos avanços teóricos proporcionados pela pesquisa na construção de um referencial com suporte de informações para a temática proposta e para discussão dos resultados. Segundo, em função de que o impacto social pode ser considerado ou verificado a partir dos dados estatísticos ilustrados e do relato dos entrevistados, os quais foram/são usuários dos serviços da referida organização ou tiveram algum familiar beneficiado por eles. Esses, reconhecem os benefícios que receberam e as oportunidades que obtiveram, pessoalmente e comunitariamente. A comparação de cada local dos três estados reforça o impacto social de todas as ações na vida das pessoas, devido ao fato de os serviços oferecidos serem de acordo com as necessidades demandadas.

A partir das compreensões permitas, este trabalho oferece literatura sobre impacto social, terceiro setor e assistência social para organizações sem fins lucrativos, o que pode ser aprofundado com novas pesquisas na área temática, visto que essa começa a ganhar espaço em estudos científicos justamente pelos impactos causados navida de pessoas vulneráveis e em risco social. 
Esta pesquisa proporciona, ainda, para os gestores das organizações sem fins lucrativos, a possibilidade de verificarem, com frequência e periodicamente, se os serviços oferecidos estão de acordo com as necessidades das comunidades atendidas. Isso, por meio da (re) aplicação do instrumento de coleta de dados construído ou por intermédio de outros meios diagnósticos e de pesquisas de satisfação, favorecendo melhorias na organização e na qualidade de vida de seus usuários, potencializando ações construtivas e de transformação social.

Sugere-se, portanto, para estudos futuros, que seja realizado, além da aplicação do questionário aos usuários, também aos gestores, permitindo a comparação das necessidades e demandas de ambos e estreitando ações para que, de fato, a organização atue, com os recursos disponíveis, transformando pessoas e lugares. Ainda, sugere-se pesquisas para identificar quais são as organizações sem fins lucrativos que divulgam nas mídias os impactos sociais causados por suas ações, destacando seus serviços, suas dificuldades e suas consequências.

\section{Referências}

ASSUMPÇÃO, J. J., \& CAMPOS, L. M. S. (2011). Avaliação de projetos sociais em ONGs da Grande Florianópolis: um estudo sobre modelos relacionados ao foco de atuação. Revista de Administração Pública, 45(1), 209-242.

ALAYON, N. (1995). Assistência e assistencialismo: controle dos pobres ou erradicaşão da pobrez̧a? São Paulo: Cortez.

ARANHA, J. S., SILVA, M. E. S., \& SILVA, J. L. L. (2011). Acolhimento e humanização: perspectiva do atendimento na atenção básica. Informe em promoção da saúde, 7(2), 23-24.

AUSTIN, J. E. (2001). Parcerias: fundamentos e beneficios para o terceiro setor. São Paulo: Futura.

BARROW, C. J. (2002). Evaluating the social impacts of environmental change and the environmental impact of social change: an introductory review on social impact assessment. Environ Stud, 59(2), 185-195.

BRITTO, C. C., \& BIT'TENCOURT, F. L. M. (2008). O terceiro setor, o princípio da subsidiariedade e a ação administrativa de fomento no horizonte de uma nova ordem social. Revista Faculdade de Direito UFG, 32(1), 35-45.
BURDGE, R. J., FRICKE, P., FINSTERBUSCH, K., FREUDENBURG, W. R., GRAMLING, R., HOLDEN, A., LLEWELLYN, L....WILLIAMS, G. (1995). Interorganizational Committee on Guidelines and Principles for Social Impact Assessment, Guidelines and principles for social impact assessment. Environmental Impact Assess, 15, 11-43.

CABRAL, E. H. S. (2011). Valores e espaço público: referenciais e instrumentos para a avaliação de projetos sociais. Revista de Administração Pública, 45(6), 1915-41.

CANAVIRE-BACARREZA, G. \& HANAUER, M. M. (2012). Estimating the impacts of Bolivia's protected areas on poverty. World Development, 41, 265-285.

CARDOSO JUNIOR, J. C., \& JACCOUD, L. (2005). Políticas sociais no Brasil: organização, abrangência e tensões da ação estatal. In L. Jaccoud (Org.). Questão social e políticas sociais no Brasil contemporâneo (p. 221). Brasília: IPEA.

CLEMENTS, T., SUON, S., WILKIE, D. S., \& MILNER-GULLAND, E. J. (2014). Impacts of protected areas on local livelihood. World Dev, 64, 125-134.

COAD, L., CAMPBEL L. A., MILES, L., \& HUMPHRIES, K. (2008). The costs and benefits of protected areas for local livelihoods: a review of the current literature. Working Paper. Cambridge, U.K: UNEP World Conservation Monitoring Centre.

Constituição da república federativa do Brasil: 1998. (1998). Brasília. Recuperado de http:/ /www.planalto.gov.br

COSTA, A. M. A. M., SILVA, K. S., \& BONAN, C. (2011). Organizações não-governamentais na área da saúde da criança - revisão da literatura. Ciência e Saúde Coeltiva, 16(7), 3181-3196.

COSTA, M. M. (2017). Assessing governmentnonprofit collaborations and density of nonprofit organizations in Brazil. Revista de Administração Pública, 20(3), 330-347.

COSTA, S. F. (2005). O serviço social e o terceiro setor. Servico Social em Revista, 7(02). Recuperado de http:// www.uel.br/revistas/ssrevista/c_v7n2_selma.htm

CUSTÓDIO, E. B., JAQUES, F. V. S., \& QUINTANA, A. C. (2013). Organizações sem fins lucrativos: um estudo bibliométrico. Revista Ambiente Contábil, 5(2), 107-127. 
DEES, J. G. (1998). Enterprising nonprofits. Harvard Business Review, 76(1), 55-67.

DUARTE, I. G., CAVALCANTE, C. E., \& MARQUES, R. R. R. (2017). Gestão de pessoas no terceiro setor: motivações dos voluntaries da Fundação Cidade Viva. Revista Organizações em Contexto, 13(25), 99-120.

EBRAHIM, A., \& RANGAN, V. K. (2014). What impact: a framework for measuring the scale and scope of social performance. California Manegement Review, 56(3), 118-141.

FERNANDES, R. C. (1994). Privado porém público: o terceiro setor na América Latina (2a ed.). Rio de Janeiro: Relume-Dumará.

FERRARO, P. J., \& HANAUER, M. M. (2014). Quantifying causal mechanisms to determine how protected areas affect poverty through changes in ecosystem services and infrastructure. Proceedings of the National Academy of Sciences, 111, 4332-4337.

FIELD, A. (2013). Discovering statistics using IMB SPSS statistics (4. ed.). Los Angeles: Sage.

GAMBARDELLA, A. (2014). Avaliação de projetos em organizações do terceiro setor. Pensamento e Realidade, 29(2), 120-137.

GIMENES, E. R., \& LEONARDO, V. S. (2009). Prestação de contas: nível de transparência nas entidades do terceiro setor. In Anais do $4^{\circ}$ Seminário Nacional Estado e Politicas Sociais (p.1-13). Cascavel, PR.

GOLDMAN, L., \& BAUM, S. (2000). Introduction. In L. Goldman (Ed.). Social impact analysis: an applied anthropology: manual (p. 1-34). Oxford: Berg Books.

GUIMARÃES, I. P., PINHO, L. A., \& LEAL, R. S. (2010). Profissionalização da gestão organizacional no terceiro setor: um estudo de caso na Fundação Instituto Feminino da Bahia. Contabilidade, Gestão e Governança, 13(3), 132-148.

GUIMARÃES, J. C. (2016). Business, arguing na revolutions: entrepreneurial initiative as social innovation tool. Revista Gestão Organizacional, 14(2), 355-366.

GURNEY, G. G., CINNER, J., BAN, N. C., PRESSEY, R. L., POLLNAC, R., CAMPBELL, S. J., TASIDIAWA, S., \& SETIAWAN, F. (2014). Poverty and protected areas: an evaluation of marine integrated conservation and development project in Indonesia. Global Environmental Change, 26, 98-107.

HOWALDT, J., DOMANSKI, D., \& KALETKA, C. (2016). Social innovation: towars a new innovation paradigm. Revista de Administração Mackenzie, 17(6), $20-44$.

JONES, N., MCGINLAY, J., \& DIMITRAPOULOS, P. (2017). Improving social impact assessment of protected áreas: a review of the literature and directions for future research. Environmental Impact Assessment Revivew, 64, 1-7.

Lei no 8.742, de 7 de dezembro de 1993. (1993). Dispõe sobre a organização da Assistência Social e dá outras providências. Brasília. Recuperado http://www. planalto.gov.br/ccivil_03/leis/L8742.htm

Lei no 13.019, de 31 de julho de 2014. (2014). Brasília.

Dispõe sobre o marco regulatório do terceiro setor ou das organizações da sociedade civil. Recuperado de < http:/ /www.planalto.gov.br/ccivil_03/_ ato2011-2014/2014/lei/113019.htm

KARKI, S. T. (2013). Do protected areas and conservation incentives contribute to sustainable livelihoods? A case study of Bardia National Park, Nepal. Journal of Environmental Management, 128, 988-999.

MACHADO, A. C. M., \& BULGACOV, S. (2010). Conteúdo estratégico em organizações do terceiro setor: possibilidades e implicações de pesquisa no campo social. Revistas de Ciências de Administração, 12(28), 40-59.

MACIEL, A. L., \& CASTILHOS, R. M. (2012). Contribuições do Terceiro Setor para o Desenvolvimento Local: os Impactos Possíveis. In Anais do $6^{\circ}$ Encontro Nacional de Pesquisadores em Gestão Social (ENAPEGS). São Paulo, SP.

MAGUIRRE, M. V.; RUELAS, G. C.; \& TORRE, C. G. (2016). Women empowerment through social innovation in indigenous social enterprises. Revista de Administração Mackenzie, 17(6), 164-190.

MANÃS, A. V., \& MEDEIROS, E. E. (2012).

Terceiro setor: um estudo sobre a sua importância no processo de desenvolvimento socioeconômico. Perspectivas em Gestão \& Conhecimento, 2(2), 15-29.

MARINHO, R. A. L., BEZERRA, V. H. B., OLIVEIRA, W. P., LIMA, R. G. S., \& SANTOS, H. 
N. (2011). Avaliação de impacto no terceiro setor: um estudo de caso na Fundação Padre Zuzinha. In Anais do $8^{\circ}$ Simpósio de Excelência em Gestão e Tecnologia (SEGeT). Resende, RJ.

MARÔCO, J. (2014). Análise estatística com o SPSS Statistics (6. ed.) Pero Pinheiro, Portugal: ReportNumber.

MONTE, T., \& CARVALHO, C. A. (2005). Poder e relações de parceira no terceiro setor. $C A D$ - Revista de Ciências da Administração, 7(14), 1-26.

MOURA, E. R. A. (2008). Avaliação de impacto, comunicação e sustentabilidades das organizações não governamentais. In Anais do $2^{\circ}$ Congresso Brasileiro Científico de Comunicação Organizacional e Relações Públicas (ABRAPCORP). Belo Horizonte, MG.

MURARO, P., \& LIMA, J. E. S. (2003). Terceiro setor, qualidade ética e riqueza das organizações. Revista FAE, 6(1), 79-88.

OLAK, P. A., \& NASCIMENTO, D. T. do. (2009). Contabilidade para entidades sem fins lucrativos (terceiro Setor) (2. ed.) São Paulo: Atlas.

OLIVINDO, W. A. A. (2015). Responsabilidades dos entes federativos na condução do sistema único de assistência social e na concretização da assistência social. In: A. F. Olivindo, S. M. C. Alves, \& S. A. Albuquerque (Org). Olhares sobre o direito à assistência social. (pp. 15-29). Brasília, DF: Fiocruz Brasília: Ministério do Desenvolvimento Social e Combate à Fome.

PESTANA, M. H., \& GAGEIRO, J. N. (2014). Análise de dados para ciências sociais: a complementaridade do SPSS (6a ed.) Lisboa: Edições Sílabo.

RYAN, William P. (1999). The new landscape for nonprofits. Harvard Business Review, 77(1), 127-136.

ROCHA, L. F. (2003). Terceiro setor. São Paulo: Malheiros.

ROCHE, C. J. R. (2000). Avaliação de impacto de ONGs: aprendendo a valoriz̧ar mudanças. São Paulo: Cortez.

RODRIGUES, M. C. P. (1998). Demandas sociais versus crise de financiamento: o papel do terceiro setor no Brasil. Revista de Administração Pública, 32(5), 25-67.

SALAMON, L., \& HELMUT K. A. (1996). Defining
The Nonprofit Sector: A Cross-National Analysis, forthcoming. Manchester: Manchester University Press.

SALINAS, A. I. A., CABRAL, R., \& IRANGO, A. (2015). Comunicación, conflitos y cambio social. Bauru: UNESP/FAAC.

SANTOS, E. F., \& SILVA, C. E. (2012). A influência das estratégias de marketing na captação de recursos para o terceiro setor. Revista Brasileira de Administração Cientifica, 3(1), 94-106.

SEN, A. (2000). Desenvolvimento como liberdade. São Paulo: Companhia das Letras.

SERJE, M. (2017). Social relations: a critical reflection on the notion of social impacts as change. Environmental Impact Assessment Review, 65, 139-146.

SHIRAISHI, G. F., \& CAMPOMAR, M. C. (2011). Atividades de marketing em organizações sem fins lucrativos: um estudo exploratório em entidades ambientalistas. Revista Pensamento \& Realidade, 26(2), 87-105.

SOUSA, M. M. F., NUNES, A. B. L. M., SOUSA, M. F., SOUSA, M. F., \& ALVES, C. C. R. A. (2013). Assistência social como política pública de direito: avanços e desafios na efetivação dos direitos sociais. In Anais da $7^{a}$ Jornada Internacional de Politicas Públicas. São Luis do Maranhão, MA.

TAVARES NETO, J. Q., \& FERNANDES, A. O. F. (2010). Terceiro setor e interesses coletivos: as alternativas sociais na busca da cidadania. Sequência, 31(60), 371-390.

TUDE, J. M., \& RODRIGUES, G. K. M. (2008). Empreendimentos de geração de recursos em ONGs: uma análise sobre seus efeitos na sustentabilidade de ONGs baianas. In Anais do $32^{\circ}$ Encontro da Associação Nacional de Pós-Graduação e Pesquisa em Administração - ENANPAD. Rio de Janeiro, RJ.

VANCLAY, F. (2002). Conceptualising social impacts. Environmental Impact Assessment Review, 22, 183- 211.

VANCLAY, F. (2003). International principles for social impact assessment. Impact Assessment and Project Appraisal, 21, 5-12.

VANCLAY, F., WITH, E. A. M., AUCAMP I., \& Franks, D. M. (2015). Social impact assessment: guidance for assessing and managing the social 
impacts of projects. Fargo: International Association for Impact Assessment.

VIEIRA, G. T., ANDRADE, C. R., CKAGNAZAROFF, I. B., MACHADO, M. J. J., CHEIB, A. C., \& ABREU, B. V. (2009). A utilização da idéia de "empoderamento" em políticas públicas e ações da sociedade civil. Cadernos Gestão Social, 2(1), 135-148.

VILA NOVA, S. (2004). Introdução à sociologia. (6a ed.) São Paulo: Atlas.

YOFFE, D. (2003). Captação de recursos no campo social. In R. Voltolini (Org.). Terceiro setor: planejamento e gestão. São Paulo: Senac.

YURUK, P., AKYOL, A., \& SIMSEK, G. G. (2017). Analysing the effects of social impacts of events on satisfaction and loyalty. Tourism Management, 60, 367378. 